\title{
Methodology for Evaluating Models of Telemental Health Delivery Against Population and Healthcare System Needs: Application to Telemental Healthcare for Rural Native Veterans
}

Jay H. Shore, MD, MPH, Cynthia W. Goss, MA,

Nancy K. Dailey, MSN, RN, and Byron D. Bair, MD, MBA

Veterans Rural Health Resource Center-Salt Lake City, Veterans Health Administration Office of Rural Health, Salt Lake City, Utah.

\section{Abstract}

Background: Rural American Indian and Alaska Native (AI/AN) Veterans face exceptional barriers to receiving quality mental healthcare. We aimed to identify models of in-person and telemental health service delivery with promise for adaptation and wide dissemination to rural AI/AN Veterans.

Methods: Our method for matching specific populations with models of care includes (1) selecting frameworks that represent the healthcare organization's goals, (2) identifying relevant service delivery models for the target population(s), (3) assessing models against the selected frameworks, and (4) summarizing findings across models. We applied this approach to rural AI/AN Veteran populations.

Results: Searches identified 13 current models of service delivery for rural AI/AN Veteran, rural $A I / A N$, and general rural Veteran populations. These models were assessed against four frameworks-the U.S. Department of Veterans Affairs' Office of Rural Health's Promising Practices, Veterans Health Administration's Guide to Mental Health Services, the Institute for Healthcare Improvement's Triple Aim Framework, and the American Indian Telemental Health Clinic framework.

Discussion: The one model used for service delivery for rural AI/AN Veterans increases access and is patient-centered but lacks operational feasibility. Models for rural AI/ANs also increase access and are patient-centered but generally lack effectiveness evaluations. Models for rural Veterans demonstrate beneficial effects on mental health outcomes but do not emphasize cultural adaptations to diverse populations.

Conclusions: Our approach to selecting models of service delivery considers the needs of operational partners as well as target populations and emphasizes large-scale im- plementation alongside effectiveness. Pending further testing, this approach holds promise for wider application.

Keywords: mental health services, North American Indian, rural population, Veterans' health, telemedicine

\section{Introduction}

A merican Indian and Alaska Native (AI/AN) Veterans who serve in the military at higher rates relative to other groups ${ }^{1,2}$ are the most rural of any Veteran population ${ }^{3}$ and suffer consequences of military services disproportionately. ${ }^{3-7}$ Studies of Veterans across multiple service eras have demonstrated that AI/AN Veterans are more likely than their white counterparts to have diagnoses of post-traumatic stress disorder (PTSD), mood disorders, substance use disorders, and traumatic brain injury. ${ }^{4,5,8}$ Despite higher prevalence of mental illness, evidence on relative use of mental health services is mixed when comparing AI/AN Veterans with white Veterans. ${ }^{8-10}$ Several barriers contribute to poorer service utilization by AI/AN Veterans, particularly rural AI/AN Veterans, including lack of health insurance, ${ }^{7,11}$ transportation problems, ${ }^{11}$ navigating the health system, ${ }^{11}$ and difficulty discussing personal matters. ${ }^{12}$ Perceived cultural barriers to accessing the U.S. Department of Veterans Affairs (VA) system include its inconvenience, its lack of outreach and assistance to AI populations, and Veterans' concerns about trust and prejudice. ${ }^{12-14}$

To improve mental health service delivery to rural AI/AN Veterans, the VA Rocky Mountain Healthcare Network (VISN 19) and Office of Rural Health (ORH) developed a unique clinical telemental health (TMH) model in partnership with the Centers for American Indian and Alaska Native Health at the University of Colorado Anschutz Medical Campus. The American Indian Telemental Health (AITMH) model of care comprises four key components: (1) mental healthcare, (2) technology (telehealth connecting a patient site and a provider site), (3) intensive care coordination, and (4) specific cultural facilitation. ${ }^{15}$ This comprehensive direct care model is distinct from other models of TMH in that the team providing 
mental healthcare also does intensive outreach and care coordination. Care coordination addresses barriers to mental wellness like homelessness, food security, and complex physical health needs but is also more resource intensive than other models. Cultural facilitation ensures care addresses unique local cultural issues and is appropriate and effective in the eyes of the community through partnerships with local representatives (Tribal Outreach Workers, Tribal Veterans Representatives, traditional healers, tribal councils). ${ }^{15,16}$

Although the AITMH clinic model has logged more than 7,500 patient visits since its inception in $2002,{ }^{15}$ with a number of studies showing its feasibility, cost benefit, and efficacy, ${ }^{17-22}$ clinics outside VISN 19 have struggled with integration into the system-wide VA mental health architecture. Local adaptation challenges operational feasibility because considerable resources are required to identify and maintain physical space and equipment for each patient clinic site.

Despite the challenges of implementing the AITMH clinic model, using telehealth to deliver care to rural AI/AN Veterans has proven effective for individual Veterans. TMH increases the efficiency of care, improves service utilization, and improves outcomes, as demonstrated in this population and others. ${ }^{23}$ As the largest provider of telehealth services in the country, VA has the capacity for increasing service to rural $\mathrm{AI} / \mathrm{AN}$ Veterans, but other models of TMH service delivery may be easier to implement and equally effective.

With support from $\mathrm{ORH}$, we undertook a review to evaluate the potential of other promising mental health service delivery models for successful application to rural AI/AN Veteran telehealth. One of the challenges of surveying the field of telehealth is how to identify which models of care best fit a specific population or service need. To our knowledge, no systematic approach exists to assess the fit of a model, ${ }^{24,25}$ despite a burgeoning number of models, treatments, and unique clinical services from which to select; therefore, we developed a process to evaluate identified models for service delivery against different frameworks for improving healthcare in both VA and non-VA settings. The aims of this article are twofold: first, we summarize the review process that we developed; second, we share our application of the review process to a specific review of service delivery models for rural AI/AN Veterans.

\section{Methods}

\section{METHODOLOGY}

We followed a stepwise process for this review:

(1) Framework selection. Identify key frameworks against which to assess clinical models. In this article, we define "framework" as a set of broad standards or guidelines for improving healthcare and "model" as a conceptualization of the way that a particular healthcare service is provided to patients.

(a) Survey literature and agency/organization guidelines for key frameworks for healthcare improvement.

(b) Choose frameworks that reflect institutional goals for improved healthcare and needs of the target population.

(c) Review and operationalize framework criteria.

(2) Model identification. Conduct a literature search to identify clinical models of care relevant to the target population and specific to the desired clinical service.

(a) For underserved populations where service delivery models are rarer, consider expanding searches to include models for populations that share some characteristics with the target population.

(b) Group identified reports, articles, and other documents by clinical model.

(3) Create a matrix to assess each clinical model against the selected framework criteria.

(4) Summarize and evaluate matrix findings.

\section{METHODOLOGY APPLICATION}

(1) Framework selection

(a) We identified candidate frameworks that emphasized mental health and that could help to assess the ability of a model to be disseminated feasibly, particularly within the VA healthcare system, as well as its potential for improving health for rural AI/AN Veterans (Figure 1). Candidate frameworks included VA goals and guidelines, broader national guidelines for healthcare improvement, and frameworks guiding treatment of rural populations and AI/AN populations.

(b) We selected four frameworks. Two frameworks-the Veterans Health Administration (VHA) Handbook for Uniform Mental Health Services in VA Medical Centers and Clinics and ORH's Promising Practices-had reasonable scope for assessing a variety of models of care and were most closely aligned with VA service needs. The Handbook for Uniform Mental Health Services defines minimum clinical requirements for VHA mental health services ${ }^{26}$ and outlines nine principles that guide VA mental healthcare. ${ }^{27}$ ORH's Promising Practices designation includes six criteria $^{28}$ increased access, strong partnerships, clinical impact, return on investment, operational feasibility, and customer satisfaction. We chose the Triple Aim Framework as representative of ideal goals of improved 


\section{SHORE ET AL.}

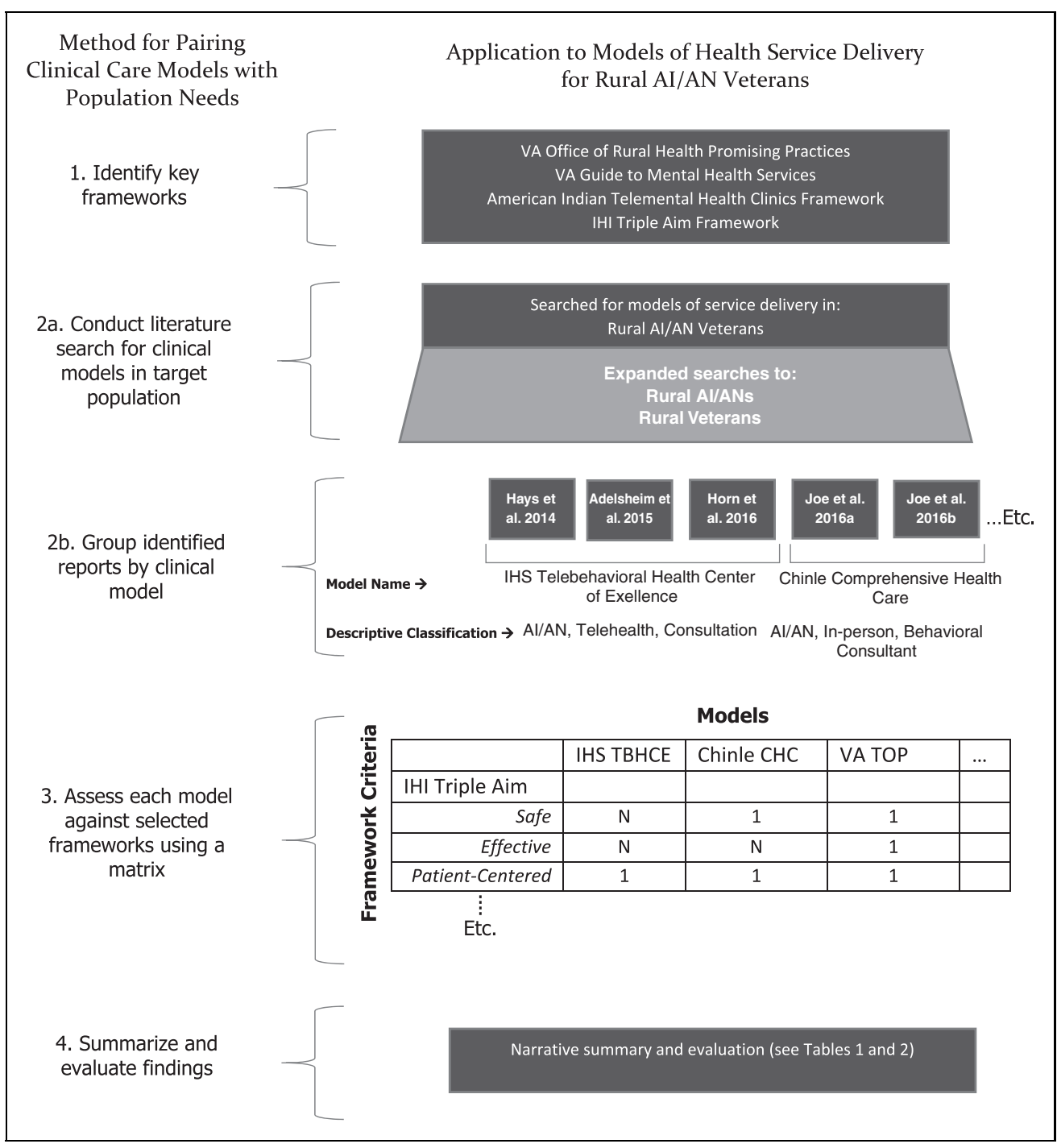

Fig. 1. Method for evaluating TMH models against population and healthcare system needs: Depiction of application to rural Al/AN Veterans. TMH, telemental health.

healthcare systems-healthier populations, satisfied patients, and decreased costs. ${ }^{29}$ We adapted the four key factors from our AITMH model of care-mental healthcare for complex conditions, technology to access remote populations, intensive care coordination, and cultural facilitation ${ }^{15}$-(the "AITMH framework") for their relevance to rural AI/AN Veterans.

(c) Publicly available descriptions of each framework defined specific criteria.

\section{(2) Model identification}

Literature searches covered publication dates 2010 and later to identify current models of service delivery. In January 2017, we searched Medline, PsycINF0, Published International Literature on Traumatic Stress (PILOTS) Database, the
Cochrane Library, and Google Scholar, using these search terms, exploding terms where possible: ((Indians, North American OR American Indian OR Native American OR Alaska Native OR Native Alaskan OR Indian Health Service) OR Veterans) AND (mental health services OR ((telebehavioral OR telepsych* ${ }^{*}$ OR telemental) AND (health services administration)) OR (("delivery of health care" OR telemedicine OR telehealth) AND (mental health OR psychology OR psychiatry))). We also performed informal searches (e.g., "snowballing," "asking around," varying search terms and combinations) to increase yield and efficiency of searches, as recommended for complex topics. ${ }^{30}$ To identify unpublished reports of models of care, we searched Google and websites of specific agencies and organizations (e.g., VA, Substance Abuse and Mental Health Services Administration, Indian Health Service [IHS], Rural Health Information Hub, Southcentral Foundation, The Commonwealth Fund). Informal searches continued until we could not locate any new relevant documents.

(a) We searched extensively to identify models for rural AI/AN Veteran populations and also expanded searches to include rural $\mathrm{AI} / \mathrm{AN}$ and rural Veteran populations. We excluded models that never targeted rural patients.

(b) We grouped results by model. To qualify for review as a model, we required a written description of delivery of mental health services in a real-world setting of sufficient detail to assess a majority of the criteria outlined by the four selected frameworks. Models of care could implement videoconferencing telehealth or in-person modes of delivery.

(3) Matrix completion

Two reviewers classified and assessed each model against criteria from each of the four frameworks, recording scores in 
a matrix. Disagreements were resolved through discussion until consensus was reached. We categorized each model by population, mode of service delivery, and one of four platforms of care-direct/referral, collaborative care, behavioral health consultant, or psychiatric consultation-liaisondrawing on Fortney et al. ${ }^{31}$ as a heuristic for resource intensity (see reference for definitions). For the Triple Aim, ORH, and AITMH frameworks, we ranked each criterion as having contradictory evidence (“-1"), supporting evidence ("1"), or inconclusive evidence ("0"). We also recorded where there was insufficient evidence to assess ("N"). For example, the ORH framework's feasibility criterion was scored as "1" if a model demonstrated success with dissemination, " -1 " if problems prevented dissemination or implementation, " 0 " if some barriers delayed but did not prevent implementation (e.g., competing staff demands), and " $\mathrm{N}$ " if there was no mention of an attempt to disseminate the model or to implement it outside a research setting. For the VA Guide to Mental Health Services framework, we assessed each criterion dichotomously (as "met" or "not met"). For example, the criterion "mental health treatment in primary care" was scored as "met" if the model uses a platform of care that, by definition, co-locates mental health providers with primary care providers, like the behavioral health consultant or psychiatric consultation platforms, or if the model described delivering mental or telemental healthcare in a primary care setting. This criterion was "not met" if the model's description did not include access to mental healthcare in the primary care setting.

\section{(4) Summary and evaluation of matrix findings}

During synthesis, we streamlined framework criteria to reduce duplication. For example, the "technology" criterion was eliminated from the AITMH framework because it reflects improved access to care, which duplicated "increased access" from the ORH framework. In addition, we consolidated the VA Guide for Mental Health and Triple Aim criteria, considering the entire framework as "met" if a majority of its criteria were "met."

\section{Results}

\section{SEARCH RESULTS}

Database searches yielded 10 relevant models (45 citations) pared from a search of 641 citations. Three additional models (12 citations) were identified from website searches. We excluded six models for lack of sufficient details and one model that was urban-only.

\section{IDENTIFIED MODELS}

We assessed the remaining 13 models, characterizing each in Table 1. No models other than the AITMH clinic model ${ }^{15,16}$ were identified for rural AIAN Veterans. We excluded one $\mathrm{AI} / \mathrm{AN}$ Veteran model because there was no indication of its use after $1995 .{ }^{32}$ Other models for Native Veteran care have not been described in the literature (e.g., Seattle Indian Health Board's Veterans and Veterans Family Program, www.rural health.va.gov/native/services). Finally, although included in evaluations of several VA mental healthcare models, ${ }^{33-35}$ $\mathrm{AI} / \mathrm{AN}$ Veterans have not been examined separately.

The few identified models for rural AI/AN populations use telehealth, hybrid, or in-person modes of delivery. Telehealth models include the IHS Telebehavioral Health Center of Excellence $^{36}$ and a partnership between the University of California Davis and tribes in California. ${ }^{37}$ Other AI/AN models include the Nuka System of Customer-Owned Care from the South Central Foundation ${ }^{38}$ and the Chinle Comprehensive Health Care Facility. ${ }^{39,40}$ We excluded other models such as the Improving Mood Promoting Access to Collaborative Treatment model of care, ${ }^{41}$ San Carlos Apache Wellness Center model, ${ }^{42}$ and the Native American Health Center's holistic system of care ${ }^{43}$ due to lack of available information or because they did not address rural populations.

Models posed by VA for rural Veterans covered all three modes of service delivery. Telemedicine outreach for PTSD or depression, ${ }^{33,44-49}$ group-based video teleconferencing therapy, ${ }^{34,50-53}$ and home-based video teleconferencing ${ }^{54-63}$ all arose from research examining the effectiveness of telemedicine. Other models include "usual" PTSD care for rural Veterans in $\mathrm{VA},{ }^{64,65}$ utilizing hybrid delivery; "usual" telemental healthcare $^{66,67}$; and primary care mental health integration with various platforms-collaborative care, ${ }^{68-71}$ behavioral consultant, ${ }^{72-75}$ or a blend of the two. ${ }^{76-78}$ Many VA models were sufficiently similar to be considered together. ${ }^{68-71}$

\section{MODEL ASSESSMENTS}

The matrix in Table 2 summarizes each model's assessment. Looking across all populations and modes of service delivery, some characteristics were rarely or insufficiently reported, including effects on population health, costs, and clinician experience (details not shown) from the Triple Aim Framework, as well as per capita costs/return on investment from the ORH Promising Practices framework.

The AITMH model ${ }^{15,16}$ unsurprisingly satisfies its own framework. Its emphasis on care coordination to meet basic needs was unique relative to other models. A focus on patientcentered care also enables it to perform well on the VA Guide to Mental Health Services and the Triple Aim Frameworks. Although it generally performed well on ORH Promising Practices, the AITMH model's lack of uptake within VA indicates challenges with operational feasibility. 
Table 1. Models of Mental Health Service Delivery in Rural AI/AN Veteran Populations, General AI/AN Populations, and General Veteran Populations

\begin{tabular}{|c|c|c|c|c|}
\hline \multirow[b]{2}{*}{ MODEL NAME } & \multicolumn{3}{|c|}{ CHARACTERISTICS } & \multirow[b]{2}{*}{ DESCRIPTION } \\
\hline & POPULATION & MODE & PLATFORM & \\
\hline AlTMH Clinics ${ }^{15-21}$ & $\begin{array}{l}\text { Rural Al/AN } \\
\text { Veteran }\end{array}$ & Telehealth & $\begin{array}{l}\text { Direct } \\
\text { care/referral }\end{array}$ & $\begin{array}{l}\text { A joint academic-community-VA partnership provides telemedicine care to patients in tribal } \\
\text { communities. The AITMH model spans the entire mental healthcare process, from outreach to } \\
\text { mental healthcare and spiritual healing to more comprehensive care coordination with other } \\
\text { service providers. The team providing mental healthcare also drives outreach and care } \\
\text { coordination. }\end{array}$ \\
\hline $\begin{array}{l}\text { IHS Telebehavioral } \\
\text { Health Center of } \\
\text { Excellence }^{36,79,80}\end{array}$ & Rural Al/AN & Telehealth & Consultation & $\begin{array}{l}\text { An IHS-academic partnership that provides care to rural Al communities through shared interview (joint } \\
\text { sessions) with a patient. Care staff at IHS facilities are connected with the community and facilitate } \\
\text { teleconferencing with a mental health expert at an academic institution. }\end{array}$ \\
\hline $\begin{array}{l}\text { California IHS } \\
\text { Telemental Health }{ }^{37,81}\end{array}$ & Rural Al/AN & Telehealth & Consultation & $\begin{array}{l}\text { A psychiatrist receives a primary care provider's request for consultation, evaluates the patient } \\
\text { via video connection, then consults to a primary care provider at an IHS site, who in turn cares } \\
\text { directly for the patient. }\end{array}$ \\
\hline $\begin{array}{l}\text { Nuka System of } \\
\text { Customer-Owned } \\
\text { Care }{ }^{38,82-88}\end{array}$ & Rural Al/AN & Hybrid & $\begin{array}{l}\text { Behavioral } \\
\text { consultant }\end{array}$ & $\begin{array}{l}\text { A tribally run system, in which tribes select entities to deliver behavioral, dental, medical, and } \\
\text { community services from a variety of providers including physicians, traditional healers, and } \\
\text { health educators. Care providers travel and telecommute to provide care in remote areas. Native } \\
\text { communities are engaged in the design, implementation, and control of their own programs. } \\
\text { Quality indicators are tracked for quality improvement activities. }\end{array}$ \\
\hline $\begin{array}{l}\text { Chinle Comprehensive } \\
\text { Healthcare Facility }\end{array}$ & Rural Al/AN & In-person & $\begin{array}{l}\text { Behavioral } \\
\text { consultant }\end{array}$ & $\begin{array}{l}\text { A tribally run comprehensive care facility that offers traditional healing to all patients. Traditional } \\
\text { healers are embedded in the practice, collaborating with doctors and accessing medical records. }\end{array}$ \\
\hline $\begin{array}{l}\text { VA Telemedicine } \\
\text { Outreach for PTSD/ } \\
\text { Depression } \\
\text { 33,44-49 }\end{array}$ & Rural Veteran & Telehealth & $\begin{array}{l}\text { Collaborative } \\
\text { care }\end{array}$ & $\begin{array}{l}\text { An offsite mental healthcare manager coordinates care for patients visiting small remote primary } \\
\text { care clinics. The care manager discusses treatment with offsite pharmacists and mental health } \\
\text { providers and shares their treatment recommendations with an onsite primary care provider. Care } \\
\text { is intensified to add telephone and videoconference consultation as needed. Cognitive behavioral } \\
\text { therapy is available to all patients via video connection. }\end{array}$ \\
\hline $\begin{array}{l}\text { VA Group-Based Video } \\
\text { Teleconferencing } \\
\text { Therapy }{ }^{34,50-53}\end{array}$ & $\begin{array}{l}\text { Rural/Remote } \\
\text { Veteran }\end{array}$ & Telehealth & $\begin{array}{l}\text { Direct } \\
\text { care/referral }\end{array}$ & $\begin{array}{l}\text { Group therapy offered via videoconferencing for remote patients with PTSD. Groups met at local } \\
\text { VA clinics or Vet Centers. }\end{array}$ \\
\hline $\begin{array}{l}\text { VA Home-Based Video } \\
\text { Teleconferencing } \\
\text { Therapy }\end{array}$ & Rural Veteran & Telehealth & $\begin{array}{l}\text { Direct } \\
\text { care/referral }\end{array}$ & $\begin{array}{l}\text { One-on-one mental health services offered in patients' homes via videoconferencing. Services } \\
\text { include medication management, psychotherapy, and therapies for PTSD, depression, anger } \\
\text { management, chronic pain, and anxiety. Patients either use their own equipment, such as a home } \\
\text { computer, tablet, or smartphone, or they receive videophones or tablets from VA. }\end{array}$ \\
\hline $\begin{array}{l}\text { VA Usual Care } \\
\text { by Video } \\
\text { Teleconferencing }\end{array}$ & Rural Veteran & Telehealth & $\begin{array}{l}\text { Direct } \\
\text { care/referral }\end{array}$ & $\begin{array}{l}\text { Traditional "hub-and-spoke" model, where patients use videoconferencing equipment at their local VA, } \\
\text { which is typically a community-based outpatient clinic, and mental health providers of all disciplines } \\
\text { videoconference from larger parent VA hospital facilities. Services include all types of therapy. }\end{array}$ \\
\hline $\begin{array}{l}\text { VA Usual Care for Rural } \\
\text { Veterans with PTSD } 64,65\end{array}$ & Rural Veteran & Hybrid & $\begin{array}{l}\text { Not } \\
\text { specified }\end{array}$ & $\begin{array}{l}\text { Care received by a sample }(n=132) \text { Veterans for PTSD at } 11 \text { medium- and large-sized } \\
\text { community-based outpatient clinics without an onsite psychiatrist. A majority of Veterans } \\
\text { received medication management and psychotherapy. Of medication management sessions, } \\
\text { psychiatrists delivered about one-third via videoconferencing, whereas primary care providers or } \\
\text { psychiatric advanced practice nurses delivered the remainder in person. Videoconferencing was } \\
\text { almost never used for psychotherapy. The majority of psychotherapy sessions occurred in a } \\
\text { group format. }\end{array}$ \\
\hline $\begin{array}{l}\text { VA Primary Care Mental } \\
\text { Health } \\
\text { Integrated Care } \\
\text { Management }^{68-71}\end{array}$ & Veteran & Hybrid & $\begin{array}{l}\text { Collaborative } \\
\text { care }\end{array}$ & $\begin{array}{l}\text { Care managers (experienced registered nurses) coordinate mental healthcare for patients with } \\
\text { depression who visit a rural medical center or community-based outpatient clinic. Care managers } \\
\text { provide brief and targeted support to primary care providers in the treatment of depression. They also } \\
\text { connect patients with a wide range of medical center and community resources. Care coordination } \\
\text { with patients occurs in-person or by telephone. Care managers also receive psychiatric consultations } \\
\text { from mental health specialists in-person or by telephone. Patients with complex conditions received } \\
\text { treatment directly from mental health specialists. }\end{array}$ \\
\hline $\begin{array}{l}\text { Primary Care Mental } \\
\text { Health Integrated } \\
\text { Co-located Collaborative } \\
\text { Care }^{72-75}\end{array}$ & Veteran & Hybrid & $\begin{array}{l}\text { Behavioral } \\
\text { consultant }\end{array}$ & $\begin{array}{l}\text { Embeds a mental health team in primary care. This team accepts warm hand-offs from primary } \\
\text { care providers and can perform same-day, streamlined mental health assessment and treatment. }\end{array}$ \\
\hline $\begin{array}{l}\text { Primary Care Mental } \\
\text { Health } \\
\text { Integrated "Blended" } \\
\text { Care }^{76-78}\end{array}$ & Veteran & Hybrid & $\begin{array}{l}\text { Behavioral } \\
\text { consultant and } \\
\text { collaborative } \\
\text { care }\end{array}$ & $\begin{array}{l}\text { This model takes variety of forms but often includes both a care manager and an on-site behavioral } \\
\text { health consultant. Patients are screened as part of a visit to their primary care provider. Care is } \\
\text { stepped to the severity of symptoms, with patients remaining under care of the primary provider, } \\
\text { undergoing phone-based assessment and treatment from a care manager, or receiving a referral } \\
\text { to a mental health specialist. Patients in immediate need may be connected with an on-site } \\
\text { behavioral health consultant for assessment and treatment. }\end{array}$ \\
\hline
\end{tabular}

Al/AN, American Indian or Alaska Native populations; AITMH, American Indian Telemental Health; IHS, Indian Health Service; PTSD, post-traumatic stress disorder; VA, U.S. Department of Veterans Affairs. 


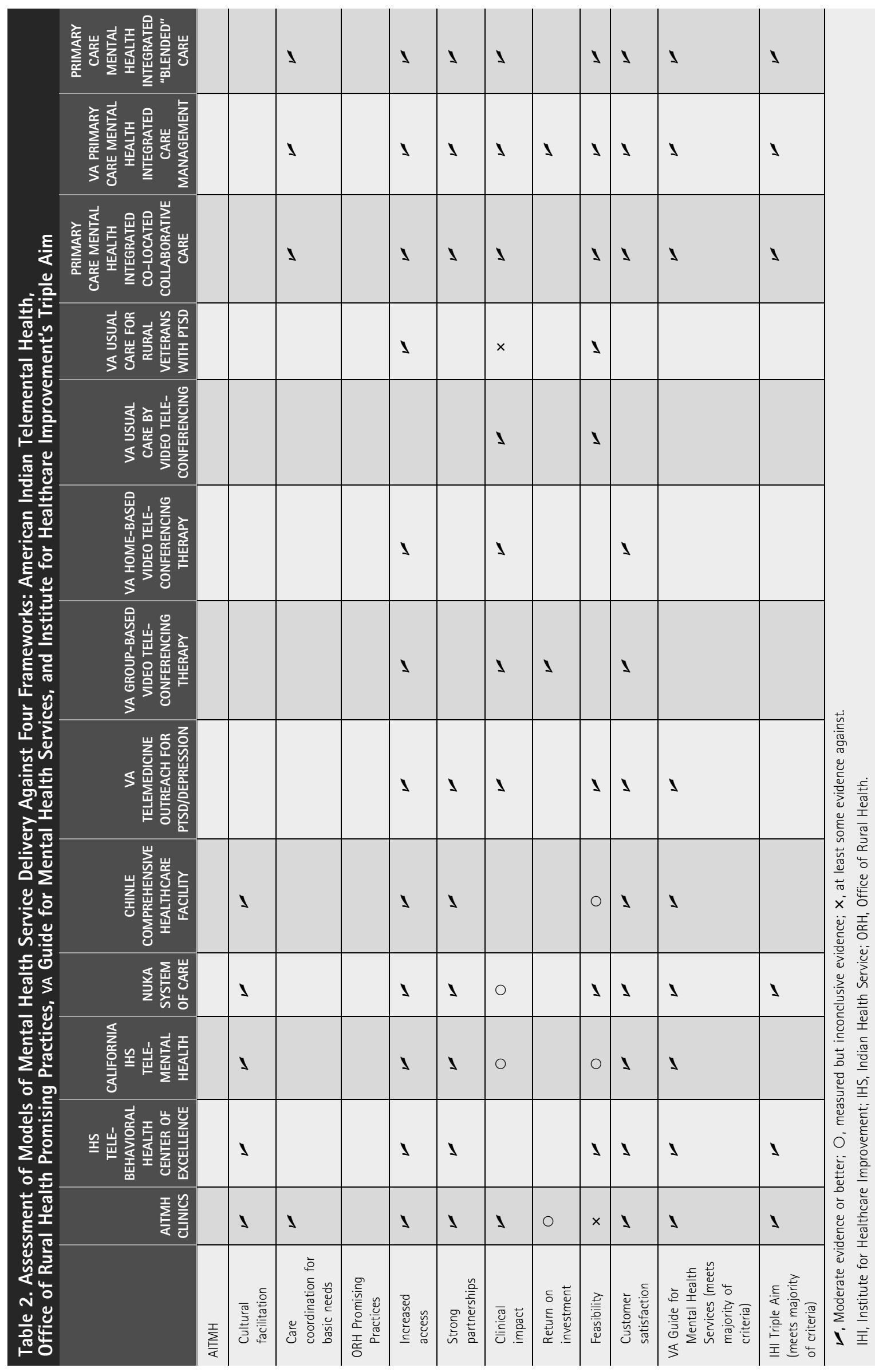




\section{SHORE ET AL.}

In general, rural AI/AN models ${ }^{36-40,79-88}$ performed well against the AITMH framework, particularly with respect to cultural facilitation, often including traditional healing or health professionals embedded in local communities. They also promote access to care, frequently establishing highquality service where none existed, and emphasizing partnerships across staff and institutions. However, clinical impact and return on investment could not be assessed due to lack of evaluations in these areas. The Telebehavioral Health Center of Excellence ${ }^{36}$ met the criterion for operational feasibility, demonstrated efficiency through reduced no-show rates, ${ }^{79}$ and reported patient and physician cost savings. ${ }^{80}$ The hybrid, tribally run Nuka System of Care, ${ }^{38,82-88}$ which cited several improvements relative to traditional government-run care, performed well against all frameworks.

In contrast to the AI/AN models, most rural Veteran models $^{33,34,44-78}$ did not specifically address elements of cultural facilitation and were weaker in terms of patient-centeredness and strong partnership; however, they did focus on clinical outcomes, demonstrating treatment effectiveness and customer satisfaction. These attributes translate to shortcomings on the AITMH and VA Guide frameworks but success against the ORH framework. The "usual" PTSD rural care model was an exception, as one study found that it rarely implemented evidence-based psychotherapy. ${ }^{64}$

Many models did not meet the majority of criteria on the Triple Aim Framework, which has strictly defined requirements and spans a variety of subjects including patient experience, reduced cost, and population health outcomes.

Almost all models increased access to care. Some clinicbased telehealth models improved access without completely remedying all access barriers. For example, older adults might not be able to drive anywhere, even to a nearby communitybased outpatient clinic.

\section{Discussion}

FINDINGS FROM THE APPLICATION OF OUR APPROACH

Many of the mental health service delivery models for rural AI/AN populations and rural Veterans did not meet criteria specified by our chosen evaluation frameworks, with specific weaknesses in the Institute for Healthcare Improvement's (IHI) Triple Aim Framework criteria, the ORH Promising Practices framework's return on investment criterion, and the AITMH framework's criteria on cultural facilitation and care coordination for basic needs. These criteria represent challenging new standards for healthcare that are likely unattainable for any single model. Nonetheless, many of these current models fell short on important components specified by evaluation frameworks.
Despite extensive searches for care models specific to rural $\mathrm{AI} / \mathrm{AN}$ Veterans, only one met our inclusion criteria. ${ }^{15,16}$ Our searches retrieved many more studies on health disparities of rural AI/AN Veterans than on treatment options for them, underscoring this population's need for more choice in mental health service delivery. Expanding searches to include rural Veterans and AI/AN populations uncovered several additional models of service delivery, most of which miss at least one key element for rural AI/AN Veterans. For example, the VA model of "usual" PTSD care for rural Veterans ${ }^{64}$ is not likely to be effective for rural AI/AN Veterans because of its limited use of evidence-based psychotherapies, absence of cultural facilitation, and gaps in access to care. Although newer VA models emphasize evidence-based care, they lack cultural facilitation. In contrast, AI/AN models of service delivery prioritize cultural facilitation, but clinical impact must be established before implementation for rural AI/AN Veterans receiving VA care.

While no single model emerged for rural AI/AN Veterans, a few models distinguish themselves. Models like the IHS Telebehavioral Health Center of Excellence ${ }^{36,79,80}$ and the Nuka System of Care ${ }^{38,82-88}$ exhibit strong cultural facilitation while maintaining operational feasibility. The care management ${ }^{68-71}$ and "blended" care ${ }^{76-78}$ models from VA also demonstrate operational feasibility while delivering effective evidence-based care. These VA models also require strong partnerships to coordinate care across a variety of healthcare staff; hence, they may be amenable to adaptation for cultural facilitation, which requires strong community partnerships to foster trust and to connect patients with a range of community-based care and services. As future steps include testing the implementation of a model selected using this approach, the most promising complementary models from VA and AI/AN populations could potentially be fused to improve healthcare delivery to a deserving population of rural AI/AN Veterans.

Our application also has implications for research. AI/AN service delivery models used consultation and behavioral health consultant platforms, which lack the evidence base of other platforms like collaborative care. Conversely, the swift uptake of care models on behavioral health consultant platforms suggests their operational feasibility over models on collaborative care platforms, which have been adopted more slowly. ${ }^{72}$ Models using behavioral health consultants are particularly popular in VA clinics serving smaller populations, ${ }^{72}$ highlighting their promise for rural areas. The operational success of these models in underserved populations like AI/ANs and rural Veterans could be reason to expedite investigation into their effects on health outcomes. 


\section{MODELS OF TELEMENTAL HEALTH DELIVERY}

Finally, this review provides insight into specific healthcare improvement frameworks. The most prominent frameworks guiding our evaluation, the IHI Triple Aim and the VA Guide to Mental Health Services, address effectiveness and costeffectiveness, patient and provider experience, access to care, and even system-wide improvement in health outcomes; however, adding ORH Promising Practices and AITMH frameworks better accounted for elements central to VHA healthcare and rural AI/AN Veterans, including culture, community, feasibility, and scalability. Thus despite their comprehensiveness, the most prominent healthcare improvement frameworks could better leverage connections between healthcare systems and culture/community.

\section{REFLECTIONS ON THE METHODOLOGY ITSELF}

Challenges of this approach stem from the heterogeneity of models of care and from the need to tailor framework selection to the healthcare system and patient population. Many models of care arise organically, with variation in terms of scope, conditions treated, and treatment methods, complicating crosscomparison of models and precluding rigid operationalization of framework criteria. Similarly, tailoring the selection of evaluation frameworks prevents comparison across reviews that use different frameworks. Both of these caveats reflect trade-offs to a pragmatic approach, which emphasizes relevance for stakeholders and widespread implementation. Ultimately, the approach strives to balance a systematic evaluation process with meaning for healthcare systems and patients. Following refinement and additional testing, this methodology holds promise for application to other populations and models of care.

\section{Acknowledgments}

This work was funded by the Veterans Rural Health Resource Center Salt Lake City, Office of Rural Health, U.S. Department of Veterans Affairs. The views expressed in this article are those of the authors and do not necessarily reflect the position or policy of the Department of Veterans Affairs. Visit www.ruralhealth.va.gov to learn more.

\section{Disclosure Statement}

No competing financial interests exist.

\section{REFERENCES}

1. Holiday L, Bell G, Klein R, Wells MR. American Indian and Alaska Native veterans: Lasting contributions. Washington, DC: VA Office of Policy Assistant Secretary for Policy, Planning, and Preparedness, 2006

2. Watkins SJ, Sherk J. Who serves in the U.S. Military? The demographics of enlisted troops and officers. Heritage Center for Data Analysis: CDA\#08-05, 2008.
3. VA Office of Health Equity. National Veteran Health Equity Report-FY 2013. Washington, DC: US Department of Veterans Affairs, 2016.

4. Beals J, Manson SM, Shore JH, et al. The prevalence of posttraumatic stress disorder among American Indian Vietnam veterans: Disparities and context. J Trauma Stress 2002;15:89-97.

5. Koo KH, Hebenstreit CL, Madden E, et al. Race/ethnicity and gender differences in mental health diagnoses among Iraq and Afghanistan veterans. Psychiatry Res 2015;229:724-731.

6. Luncheon $\mathrm{C}$, Zack M. Health-related quality of life among US veterans and civilians by race and ethnicity. Prev Chronic Dis 2012;9:110138.

7. Westat. National Survey of Veterans, Active Duty Service Members, Demobilized National Guard and Reserve Members, Family Members, and Surviving Spouses. Final Report. Rockville, MD: US Department of Veterans Affairs, 2010

8. Brooks E, Kaufman C, Nagamoto HT, et al. The impact of demographic differences on Native veterans' outpatient service utilization. Psychol Serv 2015;12:134-140.

9. Koo KH, Madden E, Maguen S. Race-ethnicity and gender differences in VA health care service utilization among U.S. veterans of recent conflicts. Psychiatr Serv 2015;66:507-513.

10. Maguen $S$, Madden $E$, Cohen $B E$, et al. Time to treatment among veterans of conflicts in Iraq and Afghanistan with psychiatric diagnoses. Psychiatr Serv 2012;63:1206-1212.

11. Johnson PJ, Carlson KF, Hearst MO. Healthcare disparities for American Indian veterans in the United States: A population-based study. Med Care 2010;48: 563-569.

12. Westermeyer J, Canive J, Thuras P, et al. Perceived barriers to VA mental health care among upper Midwest American Indian veterans: Description and associations. Med Care 2002;40:62-70.

13. Harada ND, Villa VM, Reifel N, Bayhylle R. Exploring veteran identity and health services use among Native American veterans. Mil Med 2005;170:782-786.

14. Kaufman $C E$, Kaufman $\amalg$, Shangreau $C$, et al. American Indian veterans and VA services in three tribes. Am Indian Alsk Native Ment Health Res 2016;23:64-83.

15. Goss CW, Richardson WJB, Dailey N, et al. Rural American Indian and Alaska Native veterans' telemental health: A model of culturally centered care. Psychol Serv 2017;14:270-278.

16. Shore $J H$, Kaufmann $\sqcup$, Brooks $E_{1}$ et al. Review of American Indian veteran telemental health. Telemed J E Health 2012;18:87-94.

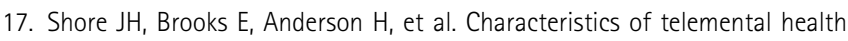
service use by American Indian veterans. Psychiatr Serv 2012;63:179-181.

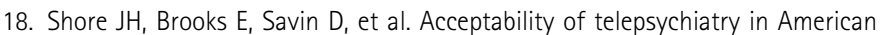
Indians. Telemed J E Health 2008;14:461-466.

19. Shore JH, Brooks E, Savin DM, et al. An economic evaluation of telehealth data collection with rural populations. Psychiatr Serv 2007;58:830-835.

20. Shore JH, Manson SM. The American Indian veteran and posttraumatic stress disorder: A telehealth assessment and formulation. Cult Med Psychiatry 2004; 28:231-243.

21. Shore JH, Manson SM. Telepsychiatric care of American Indian veterans with post-traumatic stress disorder: Bridging gaps in geography, organizations, and culture. Telemed J E Health 2004;10:64-69.

22. Shore JH, Savin D, Orton $H$, et al. Diagnostic reliability of telepsychiatry in American Indian veterans. Am J Psychiatry 2007;164:115-118.

23. Hubley $S$, Lynch $S B$, Schneck $C$, et al. Review of key telepsychiatry outcomes. World J Psychiatry 2016;6:269-282.

24. Boardman J, Parsonage M. Defining a good mental health service: A discussion paper. London: The Sainsbury Centre for Mental Health, 2005.

25. Flannery $F$, Adams $D, O$ 'Connor N. A community mental health service delivery model: Integrating the evidence base within existing clinical models. Australas Psychiatry 2011;19:49-55. 


\section{SHORE ET AL.}

26. US Department of Veterans Affairs Veterans Health Administration. VHA handbook 1160.01: Uniform mental health services in VA medical centers and clinics. Washington, DC: US Department of Veterans Affairs, 2015.

27. South Central Veterans Integrated Service Network 16 Mental IIIness Research, Education, and Clinical Center Consumer Guide Workgroup. Guide to VA mental health services for veterans \& families. Washington, DC: US Department of Veterans Affairs Veterans Health Administration, 2012.

28. Veterans Health Administration Office of Rural Health. Rural promising practices. 2017. Available at www.ruralhealth.va.gov/providers/ promising_practices.asp (last accessed September 27, 2017).

29. Stiefel M, Nolan K. A guide to measuring the Triple Aim: Population health, experience of care, and per capita cost. IHI Innovation Series white paper. Cambridge, MA: Institute for Healthcare Improvement, 2012.

30. Greenhalgh T, Peacock R. Effectiveness and efficiency of search methods in systematic reviews of complex evidence: Audit of primary sources. BMJ 2005; 331:1064-1065.

31. Fortney JC, Pyne JM, Turner EE, et al. Telepsychiatry integration of mental health services into rural primary care settings. Int Rev Psychiatry 2015;27: 525-539.

32. Scurfield RM. Healing the warrior: Admission of two American Indian war-veteran cohort groups to a specialized inpatient PTSD unit. Am Indian Alsk Native Ment Health Res 1995;6:1-22.

33. Fortney JC, Pyne JM, Edlund MJ, et al. A randomized trial of telemedicine-based collaborative care for depression. J Gen Intern Med 2007;22:1086-1093.

34. Morland LA, Mackintosh MA, Rosen CS, et al. Telemedicine versus in-person delivery of cognitive processing therapy for women with posttraumatic stress disorder: A randomized noninferiority trial. Depress Anxiety 2015;32:811-820.

35. Davis TD, Deen T, Bryant-Bedell $K_{1}$ et al. Does minority racial-ethnic status moderate outcomes of collaborative care for depression? Psychiatr Serv 2011; 62:1282-1288.

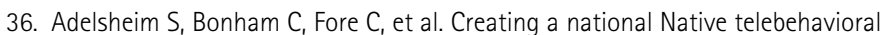
health network: The IHS Telebehavioral Health Center of Excellence. In: Roberts LW, Reicherter D, Adelsheim S, Joshi SV, eds. Partnerships for mental health: Narratives of community and academic collaboration. Cham, Switzerland: Springer International Publishing, 2015:77-88.

37. Hilty DM, Yellowlees PM, Tarui N, et al. Mental health services for California Native Americans-Usual service options and a description of telepsychiatric consultation to select sites. In: Madhavan R, ed. Telemedicine [Online]. InTech, 2013. Available at www.intechopen.com/books/telemedicine/mental-healthservices-for-california-native-americans-usual-service-options-and-adescription-of-te (last accessed November 28, 2017).

38. Gottlieb K. The Nuka System of Care: Improving health through ownership and relationships. Int J Circumpolar Health 2013;72:21118.

39. Joe JR, Young RS, Moses J, et al. At the bedside: Traditional Navajo practitioners in a patient-centered health care model. Am Indian Alsk Native Ment Health Res 2016;23:28-49.

40. Joe JR, Young RS, Moses J, et al. A collaborative case study: The Office of Native Medicine. Am Indian Alsk Native Ment Health Res 2016;23:50-63.

41. Hoeft T, Desper D. IMPACT model of collaborative care. Presentation from the 2015 National Behavioral Health Conference. Phoenix, AZ, 2015.

42. Wilshire TW. Telepsychiatry services at a tribally run behavioral health clinic. Psychol Serv 2012;9:318-319.

43. Wright $S$, Nebelkopf $E$, King J, et al. Holistic system of care: Evidence of effectiveness. Subst Use Misuse 2011;46:1420-1430.

44. Agha Z. Update on Telemedicine Outreach for PTSD-Lessons Learned: VIReC Clinical Informatics Seminar. 2011. Available at www.hsrd.research.va.gov/ for_researchers/cyber_seminars/archives/video_archive.cfm?SessionID=356 (last accessed October 13, 2017).

45. Fortney JC, Maciejewski ML, Tripathi SP, et al. A budget impact analysis of telemedicine-based collaborative care for depression. Med Care 2011;49:872-880.
46. Fortney JC, Pyne JM, Kimbrell TA, et al. Telemedicine-based collaborative care for posttraumatic stress disorder: A randomized clinical trial. JAMA Psychiatry 2015;72:58-67.

47. Grubbs KM, Fortney JC, Pyne JM, et al. Predictors of initiation and engagement of cognitive processing therapy among veterans with PTSD enrolled in collaborative care. J Trauma Stress 2015;28:580-584.

48. Liu CF, Fortney J, Vivell S, et al. Time allocation and caseload capacity in telephone depression care management. Am J Manag Care 2007;13: 652-660.

49. Pyne JM, Fortney JC, Tripathi S, et al. Cost-effectiveness analysis of a rural telemedicine collaborative care intervention for depression. Arch Gen Psychiatry 2010;67:812-821.

50. Morland LA, Greene CJ, Rosen CS, et al. Telemedicine for anger management therapy in a rural population of combat veterans with posttraumatic stress disorder: A randomized noninferiority trial. J Clin Psychiatry 2010;71:855-863.

51. Morland LA, Mackintosh MA, Greene CJ, et al. Cognitive processing therapy for posttraumatic stress disorder delivered to rural veterans via telemental health: A randomized noninferiority clinical trial. J Clin Psychiatry 2014;75: 470-476.

52. Morland LA, Pierce K, Wong MY. Telemedicine and coping skills groups for Pacific Island veterans with post-traumatic stress disorder: A pilot study. J Telemed Telecare 2004;10:286-289.

53. Morland LA, Raab M, Mackintosh MA, et al. Telemedicine: A cost-reducing means of delivering psychotherapy to rural combat veterans with PTSD. Telemed J E Health 2013;19:754-759.

54. Acierno R, Gros DF, Ruggiero KJ, et al. Behavioral activation and therapeutic exposure for posttraumatic stress disorder: A noninferiority trial of treatment delivered in person versus home-based telehealth. Depress Anxiety 2016;33: 415-423.

55. Acierno R, Knapp R, Tuerk $P$, et al. A non-inferiority trial of prolonged exposure for posttraumatic stress disorder: In person versus home-based telehealth. Behav Res Ther 2017;89:57-65.

56. Bounthavong M, Pruitt LD, Smolenski DJ, et al. Economic evaluation of home-based telebehavioural health care compared to in-person treatment delivery for depression. J Telemed Telecare 2016;24:84-92.

57. Egede LE, Acierno R, Knapp RG, et al. Psychotherapy for depression in older veterans via telemedicine: A randomised, open-label, non-inferiority trial. Lancet Psychiatry 2015;2:693-701.

58. Egede LE, Gebregziabher $M$, Walker RJ, et al. Trajectory of cost overtime after psychotherapy for depression in older Veterans via telemedicine. J Affect Disord 2017;207:157-162.

59. Gros DF, Lancaster CL, Lopez CM, Acierno R. Treatment satisfaction of home-based telehealth versus in-person delivery of prolonged exposure for combat-related PTSD in veterans. J Telemed Telecare 2018;24:51-55.

60. Shore P, Goranson A, Ward MF, Lu MW. Meeting veterans where they're @: A VA Home-Based Telemental Health (HBTMH) pilot program. Int J Psychiatry Med 2014;48:5-17.

61. Strachan M, Gros DF, Ruggiero KJ, et al. An integrated approach to delivering exposure-based treatment for symptoms of PTSD and depression in OIF/OEF Veterans: Preliminary findings. Behav Ther 2012;43:560-569.

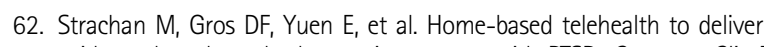
evidence-based psychotherapy in veterans with PTSD. Contemp Clin Trials 2012; 33:402-409.

63. Yuen EK, Gros DF, Price M, et al. Randomized controlled trial of home-based telehealth versus in-person prolonged exposure for combat-related PTSD in veterans: Preliminary results. J Clin Psychol 2015;71:500-512.

64. Grubbs KM, Fortney JC, Kimbrell T, et al. Usual care for rural veterans with posttraumatic stress disorder. J Rural Health 2017;33:290-296.

65. Mott JM, Grubbs KM, Sansgiry S, et al. Psychotherapy utilization among rural and urban Veterans from 2007 to 2010. J Rural Health 2015;31:235-243. 


\section{MODELS OF TELEMENTAL HEALTH DELIVERY}

66. Deen TL, Godleski L, Fortney JC. A description of telemental health services provided by the Veterans Health Administration in 2006-2010. Psychiatr Serv 2012;63:1131-1133.

67. Godleski L, Darkins A, Peters J. Outcomes of 98,609 U.S. Department of Veterans Affairs patients enrolled in telemental health services, 2006-2010. Psychiatr Serv 2012;63:383-385

68. Bauer MS, Miller C, Kim B, et al. Partnering with health system operations leadership to develop a controlled implementation trial. Implement Sci 2016; $11: 22$

69. Hoerster KD, Jakupcak M, Stephenson KR, et al. A pilot trial of telephone-based collaborative care management for PTSD among Iraq/Afghanistan war veterans. Telemed J E Health 2015;21:42-47.

70. Rubenstein LV, Chaney EF, Ober $S$, et al. Using evidence-based quality improvement methods for translating depression collaborative care research into practice. Fam Syst Health 2010;28:91-113.

71. Tew J, Klaus J, Oslin DW. The Behavioral Health Laboratory: Building a stronger foundation for the patient-centered medical home. Fam Syst Health 2010;28: 130-145.

72. Beehler GP, Funderburk JS, King PRJ, et al. The role and functions of embedded behavioral health providers in VA primary care-mental health integration: Current evidence and future directions for research. 2015. Available at www.mirecc.va.gov/cih-visn2/Documents/Research/White\%20Paper\%20.pdf (last accessed November 28, 2017).

73. Brawer PA, Martielli R, Pye PL, et al. St. Louis Initiative for Integrated Care Excellence (SLI(2)CE): Integrated-collaborative care on a large scale model. Fam Syst Health 2010;28:175-187.

74. Funderburk JS, Sugarman DE, Maisto SA, et al. The description and evaluation of the implementation of an integrated healthcare model. Fam Syst Health 2010;28:146-160

75. Pomerantz AS, Shiner B, Watts BV, et al. The White River model of colocated collaborative care: A platform for mental and behavioral health care in the medical home. Fam Syst Health 2010;28:114-129.

76. Gould CE, Huh JWT, Brunskill SR, et al. Disability and treatment outcomes for anxiety and depression in older veterans. Clin Gerontol 2015;38:268-282.

77. Huh JWT, Woodhead EL, Brunskill SR, et al. Development and evaluation of a geriatric mood management program. Fed Pract 2014;31:32-35.

78. Woodhead EL, Brunskill SR, Tenover JL, Huh JWT. Improving patient-centered care: Personal models of depression among older male veterans. Fed Pract 2013;30:12-17.

79. Hays $H$, Carroll M, Ferguson $S$, et al. The success of telehealth care in the Indian Health Service. Virtual Mentor 2014;16:986-996.

80. Horn BP, Barragan GN, Fore C, Bonham CA. A cost comparison of travel models and behavioural telemedicine for rural, Native American populations in New Mexico. J Telemed Telecare 2016;22:47-55.
81. California Telemedicine \& eHealth Center. Telemedicine and American Indians in California. Sacramento, CA. Available at www.caltrc.org/knowledge-center/ ctrc-publications/program-guides/telemedicine-and-american-indians-incalifornia (last accessed October 13, 2017).

82. Dillard DA, Christopher D. The Southcentral Foundation depression collaborative. Int J Circumpolar Health 2007;66(Suppl 1):45-53.

83. Driscoll DL, Hiratsuka V, Johnston JM, et al. Process and outcomes of patientcentered medical care with Alaska Native people at Southcentral Foundation. Ann Fam Med 2013;11(Suppl 1):S41-S49.

84. Fox R, Merrick M. Alaska Native people shaping health care: Behavioral health \& primary care integration at Southcentral Foundation. 2013. Available at www.alaskabha.org/resources (last accessed October 13, 2017).

85. Hiratsuka VY, Smith JJ, Norman SM, et al. Guideline concordant detection and management of depression among Alaska Native and American Indian people in primary care. Int J Circumpolar Health 2015; 74:28315.

86. Johnston JM, Smith JJ, Hiratsuka VY, et al. Tribal implementation of a patientcentred medical home model in Alaska accompanied by decreased hospital use. Int J Circumpolar Health 2013;72:20960.

87. Khan B, Hiratsuka WY, Dillard D, et al. Availability and deployment of telemedicine/ telehealth technologies in rural Alaska. Fed Pract 2012;29:19-21.

88. Southcentral Foundation. Southcentral Foundation Fiscal Year 2015 Progress Report. 2016. Available at www.southcentralfoundation.com/ wp-content/uploads/2017/01/Progress-Report_2016.pdf (last accessed October 13, 2017).

Address correspondence to: Cynthia W. Goss, MA

Centers for American Indian and Alaska Native Health University of Colorado Anshutz Medical Campus Mail Stop F800

Nighthorse Campbell Native Health Building 13055 E 17th Avenue Aurora, CO 80045

E-mail: cynthia.goss@ucdenver.edu

Received: March 23, 2018 Revised: June 15, 2018

Accepted: June 21, 2018

Online Publication Date: August 21, 2018 